\title{
Effects of TCAP on passive avoidance learning in the rat ${ }^{1}$
}

EDWARD M. GUROWITZ, University of Illinois College of Medicine, Chicago, Ill. DAVID A. GROSS, University of Rochester, Rochester, N.Y., and ROBERT GEORGE, University of Illinois College of Medicine, Chicago, Ill.

The drug. TCAP, which has been shown to enhance brain nucleoprotein production, has also been reported to enhance learning ability. A single injection of the drug was shown to be detrimental to passive avoidance learning, probably due to a dose-related stimulant action. Evidence is presented in support of the hypothesis that long-term effects in brain chemistry through chronic administration of the drug might be necessary to obtain facilitation of learning.

The drug TCAP $^{3}$ was reported by Egyházi \& Hydén (1961) to increase the nucleic acid and nucleoprotein content of neurons in the rabbit. Interest in theories of a chemical basis for memory (reviewed by Gurowitz, 1968) has led to research on the effects of this drug on learning and memory.

Chamberlain, Rothschild, \& Gerard (1963) investigated the effects of TCAP on avoidance conditioning and maze learning in the rat, and found that while avoidance conditioning was facilitated by a single injection of the drug, there was no effect on maze learning.

Subsequently Essman (1966) investigated the effects of chronic administration of higher doses of TCAP $(20 \mathrm{mg} / \mathrm{kg}$ vs 10 in the Chamberlain et al study) on convulsion-induced amnesia in mice. He found that the drug decreased the amnesia to a significant extent. In a later study in Essman's laboratory, Lewis (1967) administered a wide range of dosages $(10$ to $60 \mathrm{mg} / \mathrm{kg}$ ) chronically and found that prior motor training was necessary to establish a facilitatory effect of the drug on water maze performance, and that the extent of this facilitation was not related to the dosage.

Recent studies using acute administration of the drug have, however, yielded contradictory results. Brush, Davenport, \& Polidora (1966) investigated the effects of TCAP on both active avoidance and water maze learning. No differences were found between drug and placebo animals on either task. Solyom \& Gallay (1966) tested for effects of TCAP on operant conditioning and on formation of a conditioned emotional response (CER). They found that the drug significantly increased response output in the Skinner box, but had no effect on the acquisition or extinction of the CER, and concluded that the primary effect of the drug appeared to be on performance rather than on learning. That is, that the drug acted as a stimulant. McNutt (1967) found no difference between TCAP-injected and control rats in a maze learning task, using doses of $30 \mathrm{mg} / \mathrm{kg}$.

The purpose of the present study was to employ a task which would assess not only the effects of the drug on learning, but also its effects on activity, emotionality, etc. As we have noted elsewhere (Gurowitz, Lubar, Ain, \& Gross, 1967), the passive avoidance (PAR) paradigm is particularly well suited to this purpose, since an effect of the drug on learning would be evidenced as a lack of responding, while an effect on performance would be likely to cause increased responding, hence a PAR deficit.

\section{SUBJECTS}

The Ss were 40 male, Holtzman, Sprague-Dawley rats, 93 to 98 days old at the time of testing. Weights ranged from 275 to $305 \mathrm{~g}$. APPARATUS

The apparatus used consisted of a box 13.5 in. $x 11$ in. $x 12$ in., with wood sides, a metal floor, and a cardboard cover. At one end there was a removable water dish ( $20 \mathrm{cc}$ capacity) containing a copper electrode. The electrode and floor were connected to a Lehigh Valley (LV1531) constant current shock source so that whenever the $S$ drank from the dish it received a shock of $.8 \mathrm{~mA}$ with each lick. The number of shocked consummatory responses was recorded graphically on a Beckman Type RB dynograph placed in series with the shock circuit.

\section{PROCEDURE}

One week before the experiment all Ss were placed on a $23 \mathrm{~h}$ water deprivation schedule with food available ad lib. After five days on this schedule water was withheld for $48 \mathrm{~h}$ prior to beginning testing. On the test day each $\mathrm{S}$ was placed in the box for $15 \mathrm{~min}$ without the water dish to adapt it to the situation. Then the $\mathrm{S}$ was removed, the water dish placed in the box, and the shock turned on. The $S$ was replaced in the box and allowed free access to the water for $15 \mathrm{~min}$. Forty-five min prior to the initiation of the shock (i.e., $30 \mathrm{~min}$ before adaptation began), each $S$ was injected IP with 15,30 , or $45 \mathrm{mg} / \mathrm{kg}$ of TCAP in a $10 \mathrm{mg} / \mathrm{cc}$ saline solution or with $1 \mathrm{cc}$ of physiological saline solution. Thus there were four groups, each consisting of $10 \mathrm{Ss}$.

Records were scored by one of the Es, without knowledge of the group membership of the Ss. A response was scored as any deflection of the Dynograph pen of $2 \mathrm{~mm}$ or more, with the gain set at $50 \mathrm{mV} / \mathrm{cm}$. A time marker indicated $1 \mathrm{sec}$ intervals.

\section{RESULTS}

The main finding was that the drug interfered with passive avoidance learning, and that the low and intermediate dose did not differ in their effects on behavior. Group means (illustrated in Fig. 1) were $6.75( \pm 4.02)$ for controls, $16.00( \pm 12.51)$ for the low dose group, $14.50( \pm 14.19)$ for the intermediate dose group, and $37.50( \pm 25.24)$ for the high dose group. As is evident from these data, intra-group variability was extremely high, generally because of one or two Ss which were out of line with the rest of their group.

An analysis of variance indicated that significant group differences did exist $(F=5.50, \mathrm{df}=3,28, \mathrm{p}<.01)$. Further analysis by t-tests indicated that the difference between the 0 and 30 dose groups was significant $(t=2.62, \mathrm{df}=14, \mathrm{p}<.01)$, as was that between the 15 and 45 dose groups $(t=3.77$, $\mathrm{df}=14$, $\mathrm{p}<.01)$. In other words, all drug groups showed a deficit in passive avoidance learning as compared to the saline group, and the high dose of the drug caused a greater deficit than did the low or intermediate dose.

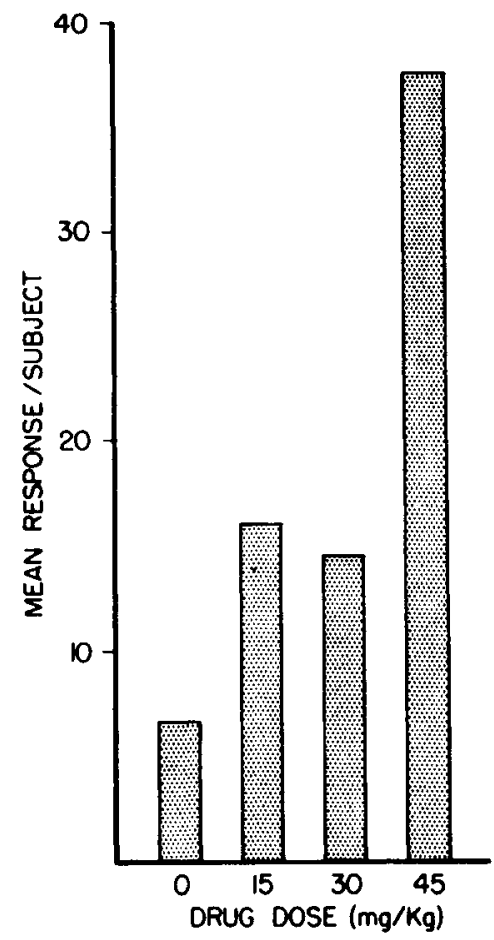

Fig. 1. Mean numbers of shocked consummatory responses for each group. 


\section{DISCUSSION}

The results of this study fail to support the hypothesis that short-term increases in brain nucleic acids and nucleoproteins are facilitatory to learning. This finding is largely in accord with the earlier work on acute administration of TCAP, as is the finding that the drug appears to have a mild stimulant effect. The only positive result in a study of acute administration was that of Chamberlain et al (1963), using an active avoidance response, where it is quite possible that heightened activity would be facilitatory to performance. It should also be noted that we used in this study doses of a higher level than those employed in past acute studies. All the earlier studies used dose levels of $15 \mathrm{mg} / \mathrm{kg}$ with the exception of McNutt (1967), who used $30 \mathrm{mg} / \mathrm{kg}$.

The failure to find enhancement of learning by TCAP does not necessarily constitute evidence against the theory of a nucleic acid-nucleoprotein basis for memory. In view of the studies of Essman (1966) and Lewis (1967), using chronic administration of TCAP, it may be that a long-term enhancement of brain production of nucleoproteins is necessary for an effect on learning. Also there is some indication from Lewis' study that chronic administration may mitigate the short term effects of the drug, since she found no difference in performance between her six dose groups. This might indicate that chronic administration of the drug leads to a habituation of the stimulant effects we observed with acute administration. Brush et al (1966) mentioned unpublished evidence indicating that chronic administration of TCAP might facilitate learning, and studies in progress in our laboratory seem to be bearing this out.

\section{REFERENCES}

BRUSH, F. R., DAVENPORT, J. W., \& POLIDORA, V. J. TCAP: Negative results in avoidance and water maze learning and retention. Psychonomic Science, 1966, 4, 183-184.
CHAMberlain, T. J., ROTHSCHLD, G. H., \& GERARD, R. W. Drugs affecting RNA and learning. Proceedings of the National Academy of Science, 1964, 52, 918-924.

EGYHÁZI, E., \& HYDÉN, H. Experimentally induced changes in the base composition of the ribonucleic acids of isolated nerve cells and their oligodendroglial cells. Journal of Biophysical \& Biochemical Cytology, $1961,10,403-410$.

ESSMAN, W. B. Effect of tricganoaminopropene on the amnesic effects of electro-convulsive shock. Psychopharmacologia, 1966, 9, 426-433.

GUROWITZ, E. M. Molecular basis of memory. Englewood Cliffs, N.J. Prentice-Hall, 1968 (in press).

GUROWITZ, E. M., LUBAR, J. F., AIN, B. R., \& GROSS, D. A. Disruption of passive avoidance learning by magnesium pemoline. Psychonomic Science, 1967, 8, 19-20.

LEWIS, S. Maze acquisition and nucleic acid metabolism: effects of two malononitrile derivatives. Paper presented at the meeting of the Eastern Psychological Association, Boston, April, 1967.

McNUTT, L. 1, 1, 3-tricyano-2amino-1-propene: a pharmacological attempt to enhance learning ability. Proceedings, 75 th Annual Conventional of the American Psychological Association, 1967, 2, 77-78.

SOLYOM, L., \& GALLAY, H. M. Effect of malononitrile dimer on operant and classical conditioning of aged white rats. International Journal of Neuropsychiatry, 1966, 2, 577-584.

\section{NOTES}

1. Supported in part by PHS Grant No. STIMH 8396.

2. Now at Department of Psychology, C. W. Post College, Brookville, N.Y. 3. A dimer of malononitrile characterized chemically as 1,1 , 3-tricyano-2-amino-1-propene. The drug is also known as Upjohn Co. compound U.9189, tri-a-p, tricyanoaminopropene and tricyamp. We are indebted to the Upjohn Co. for their kind donation of a saline soluble preparation of the drug. 